\title{
EXPERIMENT ON HYDROSTATIC THRUST BEARINGS IN MIXED LUBRICATION FOR HIGH PRESSURE HYDRAULIC PUMPS AND MOTORS
}

\author{
Toshiharu KAZAMA*, Atsushi YAMAGUCHI*, \\ Xiongying $\mathrm{WANG}^{* *}$ and Yoshimichi $\mathrm{AKASAKA}^{\dagger}$ \\ DDepartment of Mechanical Systems Engineering, Muroran Institute of Technology \\ 27-1, Mizumoto-cho, Muroran, 050, JAPAN \\ "Department of Mechanical Engineering and Materials Science, Yokohama National University \\ 156, Tokiwadai, Hodogaya-ku, Yokohama, 240, JAPAN \\ ${ }^{\dagger}$ Mechanical Engineering Research Laboratory, Hitachi, Ltd. \\ 502, Kandatsu-machi, Tsuchiura, 300, JAPAN
}

\begin{abstract}
For the maximum supply pressure of $62 \mathrm{MPa}$ (the maximum load of $15 \mathrm{kN}$ ) and the maximum speed of rotation of $25 \mathrm{~s}^{-1}$, the characteristics of circular hydrostatic thrust bearings for high pressure hydraulic pumps and motors in mixed to fluid film lubrication were studied experimentally. The diameter of the bearings tested was $20 \mathrm{~mm}$ and their surface was roughened in the region of 0.02 to $5 \mu \mathrm{mRa}$. A fluid tested was an ISO VG 32 hydraulic fluid. The frictional torque and the leakage flow rate were measured. The power losses were increased as the supply pressure, speed of rotation and surface roughness became large. The minimum power loss was obtained by a ratio of the load to the maximum hydrostatic load-carrying capacity being close to unity. Introducing a representative power loss, one could normalize the power losses in the supply pressure ranging from 0.98 to $62 \mathrm{MPa}$ and the speed of rotation ranging from 1.7 to $25 \mathrm{~s}^{-1}$.
\end{abstract}

\section{KEY WORDS}

Tribology, Hydrostatic bearings, Mixed lubrication, High pressure hydraulic pumps and motors, Experiment

$\begin{array}{cl}\text { NOMENCLATURE } & L=\text { power loss } \\ a=\text { radial ratio of recess } & l_{\mathrm{c}}=\text { length of restrictor } \\ f_{0}=\text { coefficient of friction }=-2 T /\left[(1+a) R_{2} W\right] & N=\text { speed of rotation } \\ \end{array}$




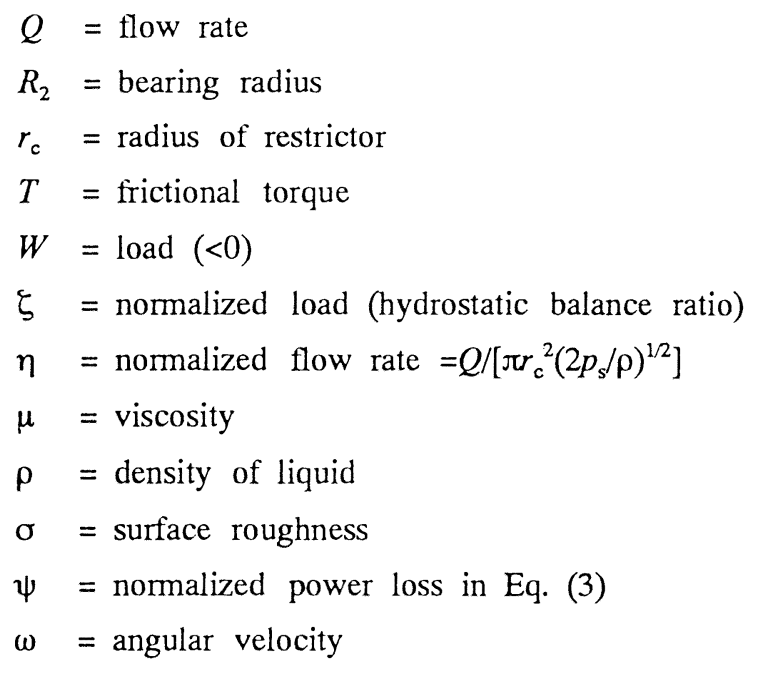

\section{INTRODUCTION}

This paper is aimed at clarifying experimentally the characteristics of hydrostatic bearings for hydraulic pumps and motors in mixed to fluid lubrication at high pressure. Since hydraulic pumps and motors are required to be operated under the condition of the high pressure and their reliability, performance and efficiency are greatly influenced by their bearing and seal parts which have a function of hydrostatic bearings. Nevertheless, there have been few experimental and theoretical studies on hydrostatic bearings for hydraulic equipment.

In previous papers, the authors clarified theoretically the characteristics of hydrostatic bearings [1] by use of a mixed lubrication model applicable to bearing and seal parts for hydraulic equipment [2]. Also, they carried out the experiment of circular hydrostatic thrust bearings supporting concentric loads and clarified experimentally the characteristics of the friction, leakage flow rate and power loss in mixed to fluid lubrication [3]. The experiment was performed successfully and its results were in good agreement with the theory [1]. The experimental conditions were, however, confined to the supply pressure of 4.9 $\mathrm{MPa}$ and the speed of rotation of $5.0 \mathrm{~s}^{-1}$, which were somewhat smaller than the operating conditions of hydraulic equipment. Thus, there is a need of efforts to investigate at the high pressure and speed operating condition.

In this paper, thereby, the experiment on the hydrostatic bearings in the regions up to the supply pressure of $62 \mathrm{MPa}$, the load of $15 \mathrm{kN}$ and the speed of rotation of $25 \mathrm{~s}^{-1}$ is made. The effects of surface roughness, supply pressure, loads and speed of rotation are clarified. Moreover, these experimental data are compared with the theoretical results.

\section{EXPERIMENTAL APPARATUS}

Figure 1 shows the schematic diagrams of the experimental apparatus. This apparatus was a circular hydrostatic thrust bearing supporting concentric loads. The test bearings consisted of two cylindrical specimens which were installed so that these endsurfaces were contacted. The upper specimen whose radius was $R_{2}$ had a hollow core, namely, a hydrostatic recess (radial ratio $a$ ). Table 1 shows the representative dimensions and experimental conditions.

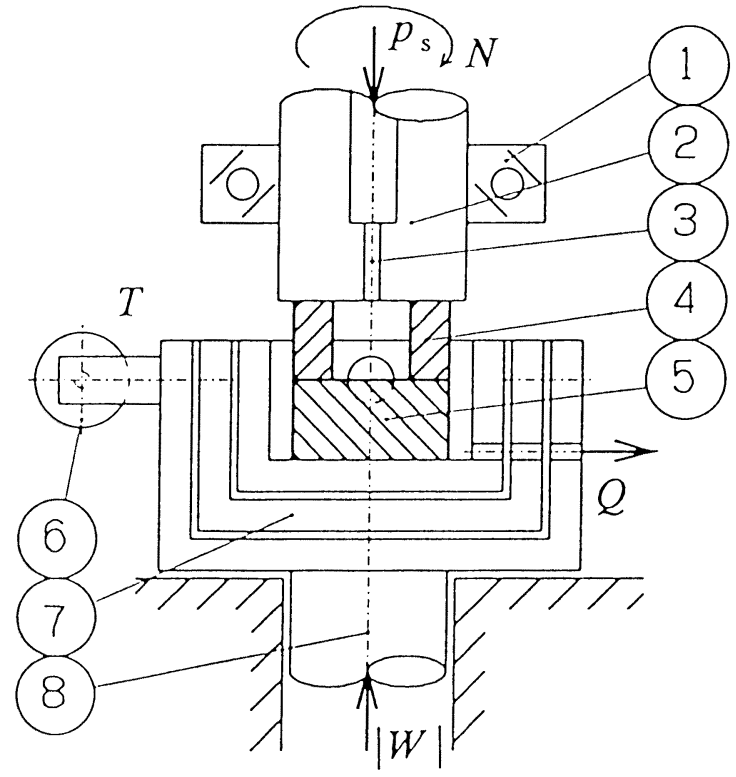

Figure 1 Test apparatus (1)Ball bearings, (2)Upper joumal, (3Restrictor, (4)Upper specimen, (5)Lower specimen, (6)Load cell, (7)Gimbals, (8) Lower journal and Hydraulic cylinder) 
Table 1 Dimensions and experimental conditions

\begin{tabular}{llll}
\hline$a$ & $=$ & 0.5 & \\
$l_{\mathrm{c}}$ & $=$ & 30 & $\mathrm{~mm}$ \\
$N_{\max }$ & $=$ & 25 & $\mathrm{~s}^{-1}$ \\
$p_{\mathrm{s}, \max }$ & $=$ & 62 & $\mathrm{MPa}$ \\
$r_{\mathrm{c}}$ & $=$ & 1.0 & $\mathrm{~mm}$ \\
$R_{2}$ & $=$ & 10 & $\mathrm{~mm}$ \\
\hline
\end{tabular}

The pressurized test fluid (supply pressure $p_{\mathrm{s}}$ ) was supplied to the hydrostatic recess through a restrictor whose length and radius were $l_{c}$ and $r_{c}$, respectively. The upper specimen was rotated with a constant speed of rotation $N$ by an electric motor (7.5 $\mathrm{kW}$ ). To avoid the tilt of the clearance between the upper and lower specimens, the lower specimen was attached by gimbals mounted on a lower journal. The static load $|W|$ was acted on the lower journal by a hydraulic cylinder.

In this experiment, the frictional torque $T$, the leakage flow rate $Q$ and the temperature of the supply and leaked fluids were measured. The frictional torque acting on the lower specimen was measured by a load-cell sensor. The leakage flow rate was measured by using a measuring cylinder (i.e., by measuring the volume in a period) for the larger leakage flow rate, and by absorbing the leaked fluid from the bearings clearance in industrial wipers and measuring the mass of the wipers before and after wipe by a precision balance (i.e., by measuring the mass in a period) for the infinitesimal leakage flow rate. The temperature was measured by thermistors.

The upper and lower specimens were made of carbon steel (S45C in the Japanese Industrial Standards; JIS, $0.42 \sim 0.48 \% \mathrm{C}$ ) and bearing steel hardness (SUJ2 in JIS; 0.95 1.10\%C, 1.30 1.60\% Cr), respectively. Both specimens were hardened by standard heat treatment (the Shore hardness $H_{s}$ of the upper and the lower specimens was $H_{\mathrm{s}}=31-40$ and $H_{s}>80$, respectively). The waviness of both specimens was removed first by lapping. The upper specimens were treated by lapping to obtain the various surface roughness $\sigma_{2}(=0.02 \sim 5 \mu \mathrm{mRa})$.

Hydraulic fluid (ISO VG 32; viscosity $\mu=27.2$ $\mathrm{mPa} \cdot \mathrm{s}$, density $\rho=850 \mathrm{~kg} / \mathrm{m}^{3}$ at $313 \mathrm{~K}$ ) was used as the test fluid. To remove contaminants in the fluid, hydraulic filters of $3 \mu \mathrm{m}$ of the nominal filtrationparticle-size were installed of both on- and off-lines.

\section{EXPERIMENTAL RESULTS AND DISCUSSION}

The operating conditions are represented by a hydrostatic balance ratio $\zeta$ which is defined by the ratio of the load to the maximum load-carrying capacity and the characteristics are evaluated by a power loss $L$ which is defined by the summation of the power loss due to leakage flow rate $L_{\mathrm{Q}}$ and that due to friction $L_{\mathrm{T}}$, namely

$$
\begin{aligned}
& \zeta=2 W \log a /\left[\pi\left(1-a^{2}\right) p_{s} R_{2}^{2}\right] \\
& L=L_{Q}+L_{T}=p_{s} Q+\omega T
\end{aligned}
$$

According to the definition in Eq. (1), $\zeta<1$ and $\zeta>1$ refer to fluid and mixed lubrication, respectively. Moreover, it should be mentioned that the optimum design criterion of the bearing and seal parts of hydraulic equipment is adopted to be minimized the power loss [4] which dominates the total efficiency of the equipment.

Figures 2 and 3 show the effects of the supply pressure $p_{\mathrm{s}}$ and the speed of rotation $N$ on the power $\operatorname{loss} L$ at high pressure, respectively. $L$ was increased as $p_{s}$ became large. $L$ was also increased with increasing $N$ in mixed lubrication. For both cases, $L$ was minimized at $\zeta \sim 1$. These results coincided with the previous data at the low supply pressure of 0.98 MPa [3]. 


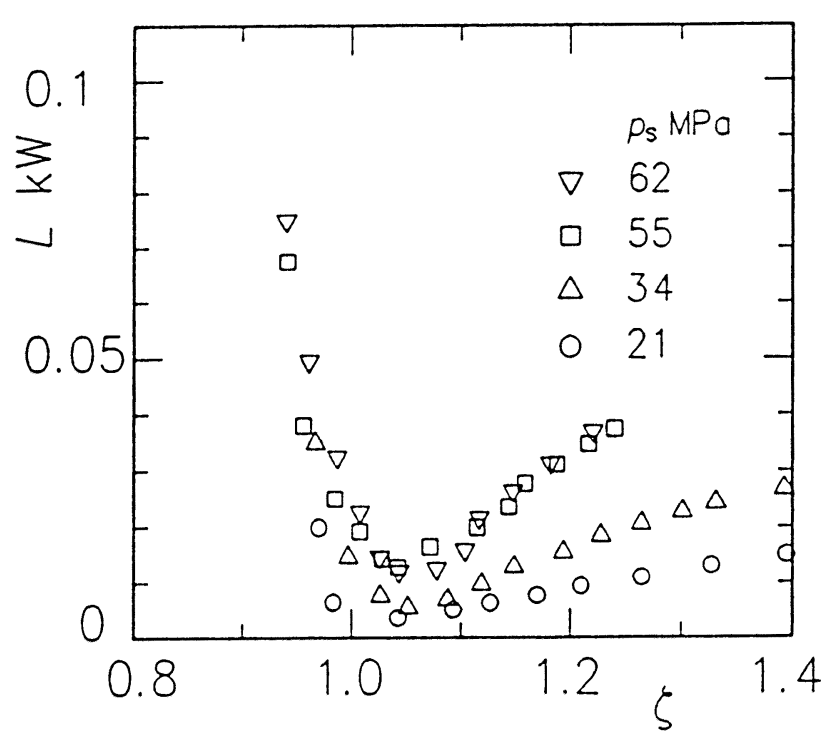

Figure 2 Effects of supply pressure $p_{\mathrm{s}}$ on power loss $L\left(N=1.67 \mathrm{~s}^{-1}, \sigma_{2} / \sigma_{1}=3.43 / 0.06: \mu \mathrm{m}\right)$

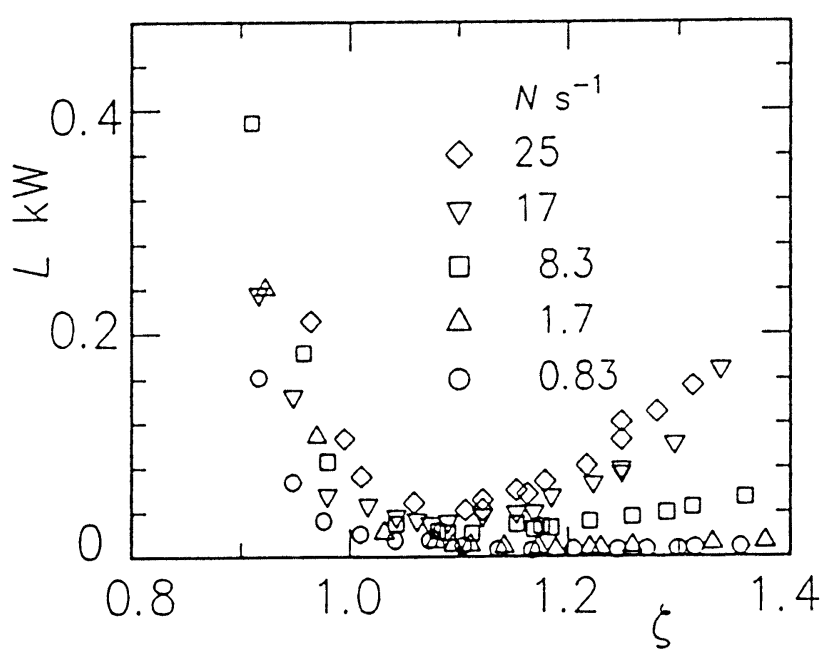

Figure 3 Effects of speed of rotation $N$ on power loss $L\left(p_{s}=21 \mathrm{MPa}, \sigma_{2} / \sigma_{1}=3.70 / 0.03: \mu \mathrm{m}\right)$

Figure 4 shows the effects of surface roughness $\sigma$ on the power loss $L$ (where, $\sigma_{1}$ and $\sigma_{2}$ refer to the surface roughness of stationary and sliding surfaces, respectively). $L$ was increased as $\sigma$ became large in $\xi>1$ but was independent of $\sigma$ in $\xi<1$, because the surfaces were contacted partially in $\xi>1$ and the frictional torque due to asperity was much greater than that due to fluid. $L$ was also minimized at $\zeta \approx 1$.

From these results, one can conclude that the

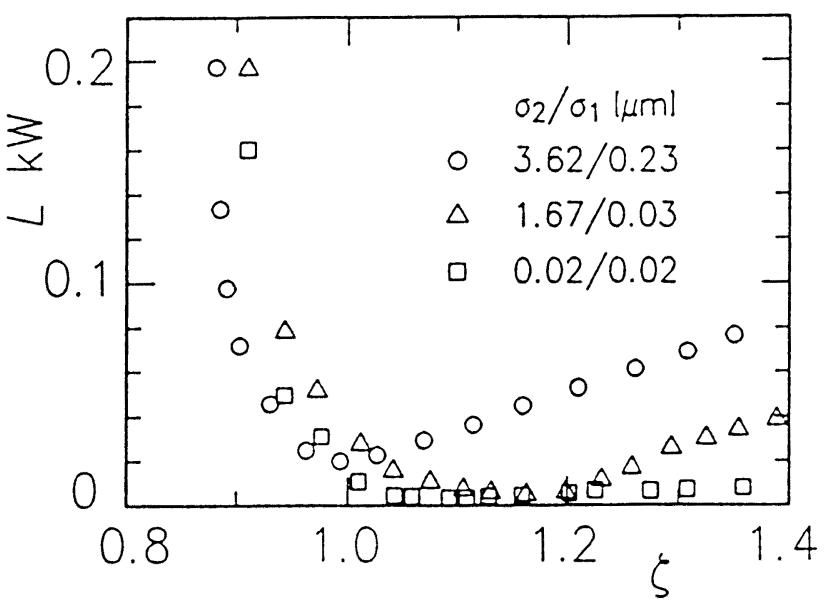

Figure 4 Effects of surface roughness $\sigma$ on power loss $L\left(p_{\mathrm{s}}=62 \mathrm{MPa}, N=1.67 \mathrm{~s}^{-1}\right)$

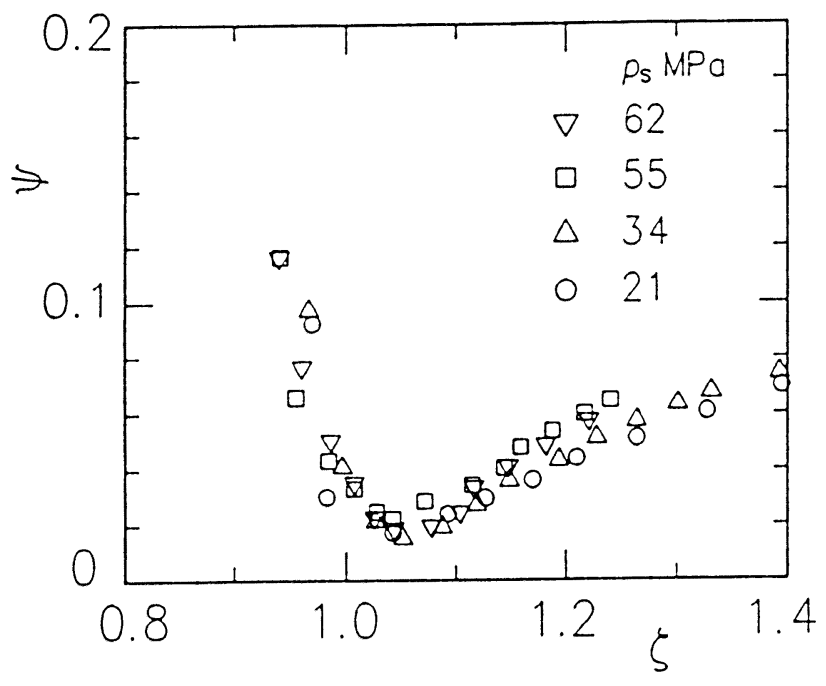

Figure 5 Normalized power loss $\psi$ for changes in supply pressure $p_{\mathrm{s}}$ (Figure 2)

case where $\zeta=1$ can be taken as the optimum design criterion, regardless of the operating conditions.

Moreover, we consider to normalize the parameters. The operating conditions (loads) have been normalized by $\zeta$ but the power losses have not been done yet. This is inconvenient for designers. Now, we introduce the normalized power loss $\psi$ defined by

$$
\psi=L /\left(\omega p_{s} R_{2}^{3}\right)
$$




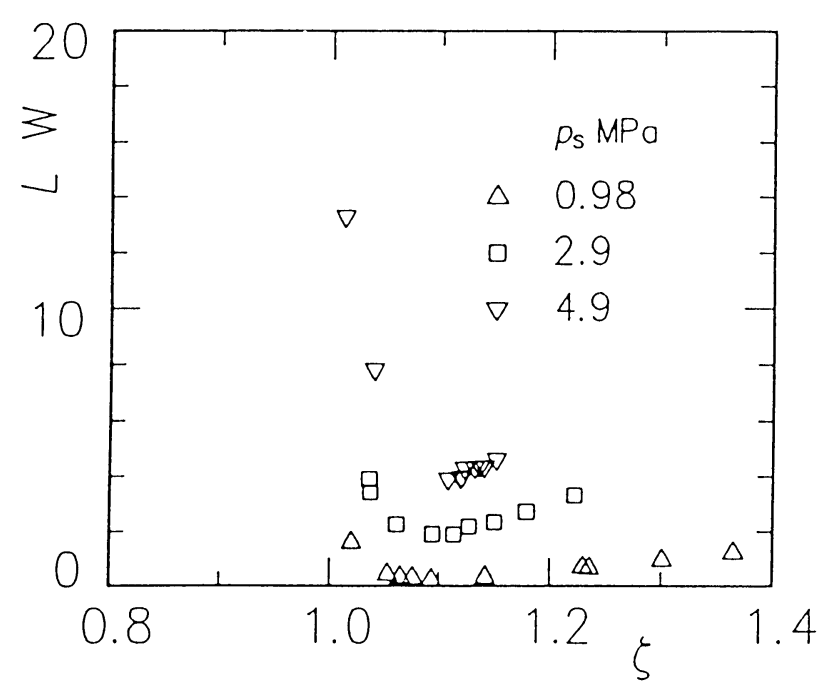

Figure 6 Power loss $L$ for $p_{\mathrm{s}} \leq 4.9 \mathrm{MPa}\left(N=1.67 \mathrm{~s}^{-1}\right.$, $\left.\sigma_{2} / \sigma_{1}=6.40 / 0.05: \mu \mathrm{m}\right)[3]$

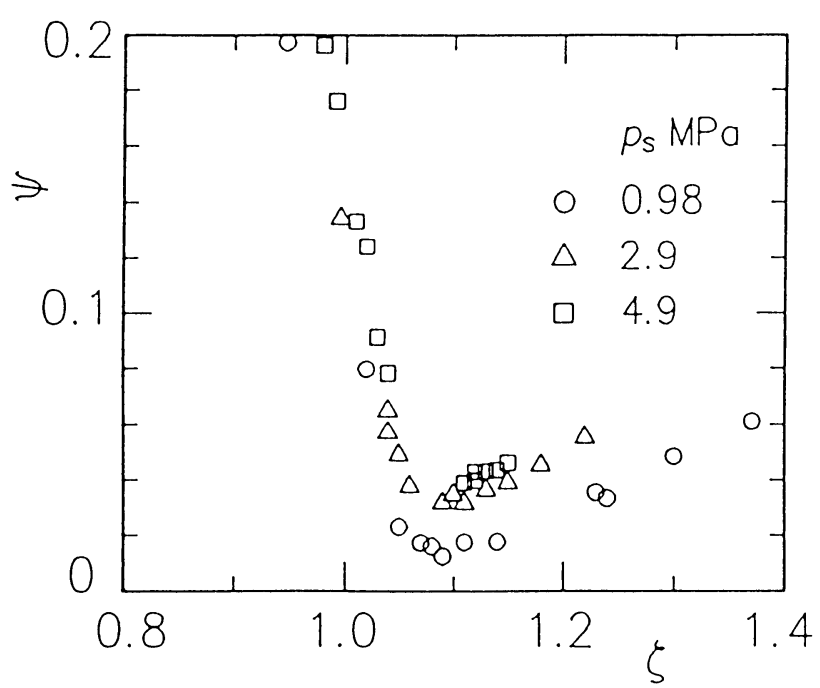

Figure 7 Normalized power loss $\psi$ for Figure 6

where $\omega, p_{\mathrm{s}}$ and $R_{2}$ are the angular velocity, supply pressure and bearing radius, which are the representative operating conditions and dimension.

Figure 5 shows the normalized power loss $\psi$ against Fig. 2. In this ligure, one can find that $L$ is normalized by $\psi$. Since the power loss $L_{0}$ due to leakage flow rate played a role of the total power loss $\left(L_{\mathrm{Q}} \gg L_{\mathrm{T}}\right)$ in fluid lubrication $(\zeta<1)$ and the power loss $L_{\mathrm{T}}$ due to friction also played a role of that $\left(L_{\mathrm{T}}>>L_{\mathrm{Q}}\right)$ in mixed lubrication $(\xi>1)$. This concludes that the parameter $\psi$ is very useful for evaluating the characteristics of hydrostatic bearings.

In addition, we examine the validity of this parameter $\psi$ for the case where $p_{\mathrm{s}, \max }=4.9 \mathrm{MPa}$ and $N_{\max }=5.0 \mathrm{~s}^{-1}$ (in this experiment; $R_{2}=12.5 \mathrm{~mm}, a$ $\left.=0.640, l_{\mathrm{d}} r_{\mathrm{c}}=7.0 / 0.525: \mathrm{mm}\right)[3]$. Figure 6 shows the effects of the supply pressure $p_{\mathrm{s}}$ on the power loss $L$ at low pressure and speed, and Fig. 7 shows the rearranged results by use of Eq. (3). In the same way as the previous rearrangement, $L$ is normalized. Besides, it should be noted that the order of $\psi$ in Fig. 7 is almost the same as $\psi$ in Fig. 5 (in this experiment, $\psi_{\min } \sim 0.02$, which is the optimum value).

\section{COMPARISON OF EXPERIMENT AND THEORY}

The detail of the theory was described in the previous papers [1-2]. In this paper, the isothermal condition acting concentric loads in the steady state is assumed.

Figures 8 through 10 show the comparison of the experimental data and the theoretical results for the coefficient of friction $f_{0}$, the normalized flow rate $\eta$ and the power loss $L$. The experimental data are in good agreement with the theoretical results for $f_{0}$

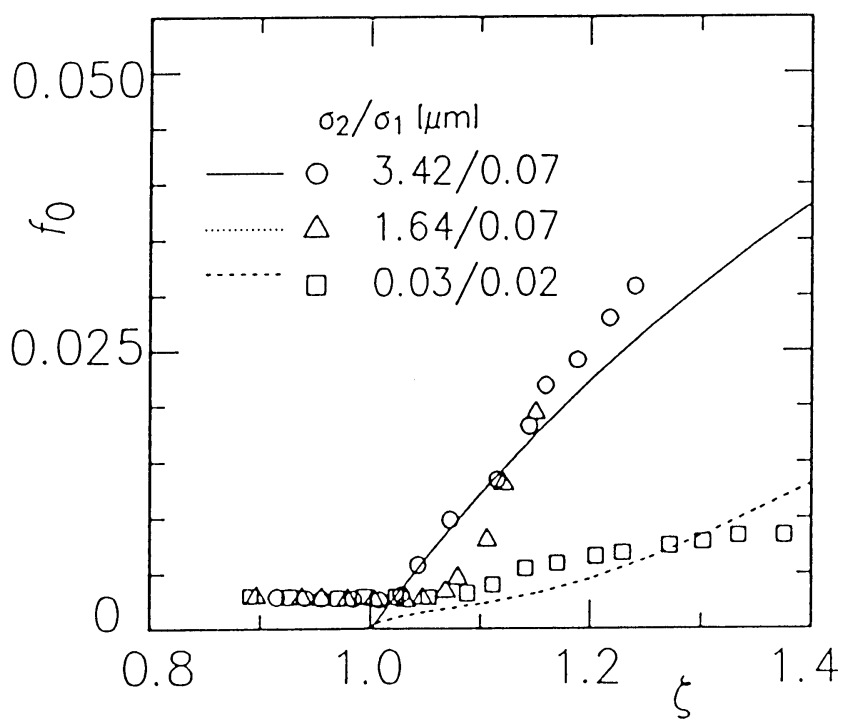

Figure 8 Comparison of experiment and theory for $f_{0}$ $\left(p_{\mathrm{s}}=55 \mathrm{MPa}, N=1.67 \mathrm{~s}^{-1}\right)$ 


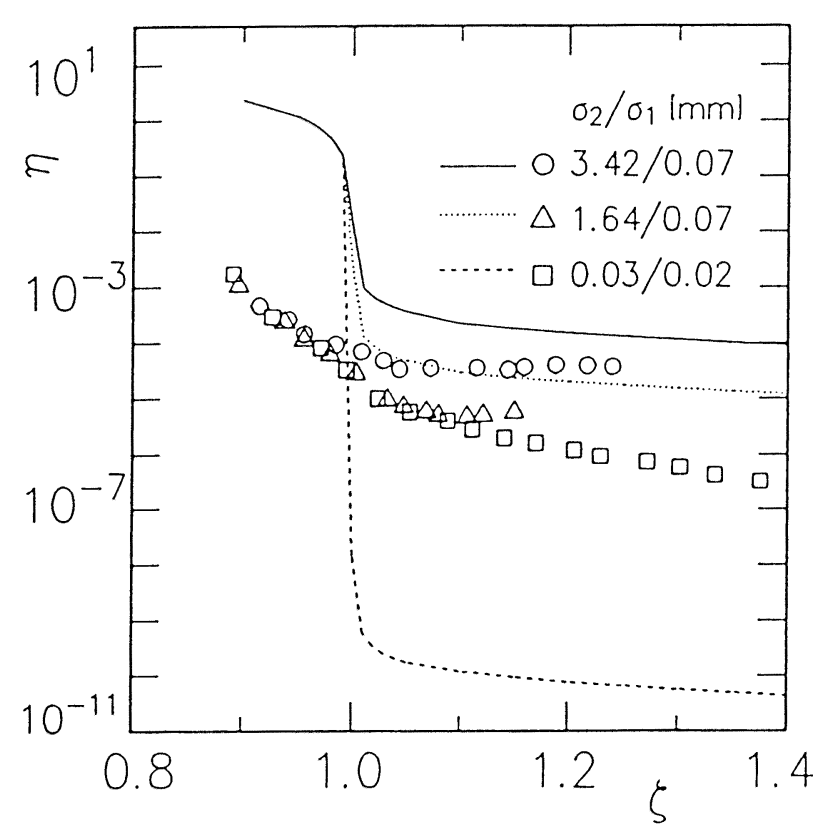

Figure 9 Comparison of experiment and theory for normalized leakage flow rate $\eta$

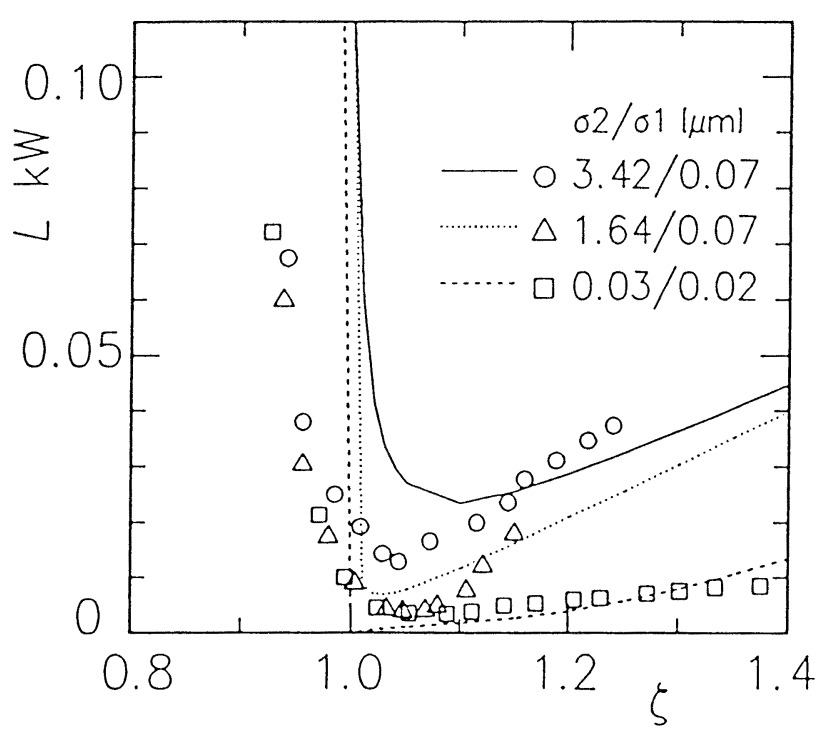

Figure 10 Comparison of experiment and theory for power loss $L$

and $L$ (in Fig. 8, the solid and dotted lines are overlapped). Further, if the surface roughness o was large, the minimum of $L$, which was close to $\zeta \sim 1$, was increased and moved to the right. Since the clearance was increased, in turn, the leakage flow rate in mixed lubrication $(\zeta>1)$ became large. In these figures, the primary cause of the differences between experiment and theory for $\eta$ was the fact that the thermal and elastic effects in the theory were neglected and the measurement of the infinitesimal leakage flow rate in the experiment was in difficulty.

\section{CONCLUSION}

The experiment of hydrostatic bearings at the operating conditions up to the supply pressure of 62 $\mathrm{MPa}$ and the speed of rotation of $25 \mathrm{~s}^{-1}$ in mixed to fluid lubrication was performed and compared with the theoretical results. Also, the characteristics of hydrostatic bearings can be expressed by using $\zeta$ and $\psi$ for the wide ranges of the operating conditions.

\section{ACKNOWLEDGEMENTS}

The authors wish to express their thanks to $\mathrm{Mr}$. T. Yokomori of Hitachi Tsuchiura Eng. Co. Ltd., Mr. I. Nakamura of Hitachi Ltd., and Messrs. N. Ohde and T. Kobayashi of Yokohama National University.

\section{REFERENCES}

1. Kazama, T. and Yamaguchi, A., Application of A Mixed Lubrication Model for Hydrostatic Thrust Bearings of Hydraulic Equipment, Trans. ASME, J. Trib., 115, 1993, pp. 686-691.

2. Yamaguchi, A. and Matsuoka, H., A Mixed Lubrication Model Applicable to Bearing/Seal Parts of Hydraulic Equipment, Trans. ASME, J. Trib., 114, 1992, pp. 116-121.

3. Kazama, T. and Yamaguchi, A., Experiment on Mixed Lubrication of Hydrostatic Thrust Bearings for Hydraulic Equipment, Trans. ASME, J. Trib., 117, 1995, pp. 399-403.

4. Kazama, T. and Yamaguchi, A., Optimum Design of Bearing and Seal Parts for Hydraulic Equipment, Wear, 161, 1993, pp. 161-171. 